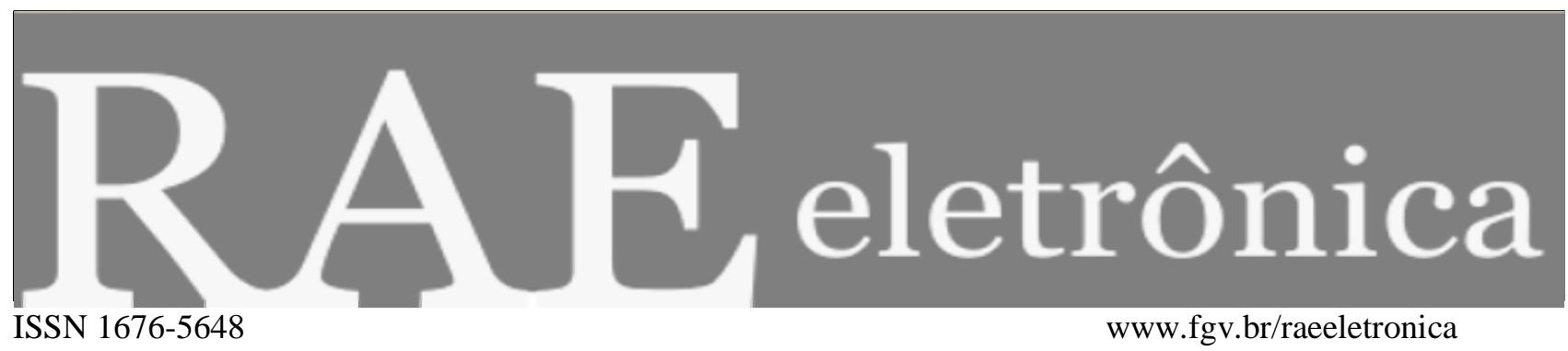

\title{
ARTIGOS
}

\section{IMPACTOS DO INÍCIO DA HARMONIZAÇÃO CONTÁBIL INTERNACIONAL (LEI 11.638/07) NOS RESULTADOS DAS EMPRESAS ABERTAS}

\section{IMPACTS OF THE INITIAL INTERNATIONAL ACCOUNTING HARMONIZATION (LAW 11.638/07) ON PUBLIC FIRMS' RESULTS}

\section{IMPACTOS DEL INICIO DE LA ARMONIZACIÓN CONTABLE INTERNACIONAL (LEY 11.638/07) EN LOS RESULTADOS DE LAS EMPRESAS ABIERTAS}

\section{Edilene Santana Santos}

Professora da Escola de Administração de Empresas de São Paulo, Fundação Getulio Vargas - São Paulo - SP, Brasil

edilene.santos@fgv.br

\section{Laura Calixto}

Doutoranda em Administração de Empresas, Escola de Administração de Empresas de São Paulo, Fundação Getulio Vargas - São Paulo - SP, Brasil

lauracalixto@uol.com.br

Recebido em 24.08.2009. Aprovado em 13.05.2010. Disponibilizado em 08.06.2010

Avaliado pelo sistema double blind review

Editor Científico: Joanília Neide de Sales Cia

RAE-eletrônica, v. 9, n. 1, Art. 5, jan./jun. 2010.

http://www.rae.com.br/eletronica/index.cfm?FuseAction=Artigo \&ID=5589\&Secao=ARTIGOS\&Volume=9\&Numero=1\& $\mathrm{Ano}=2010$

CCopyright 2010 FGV-EAESP/RAE-eletrônica. Todos os direitos reservados. Permitida a citação parcial, desde que identificada a fonte. Proibida a reprodução total. Em caso de dúvidas, consulte a Redação: raeredacao@fgv.br; 55 (11) 3799-7898.

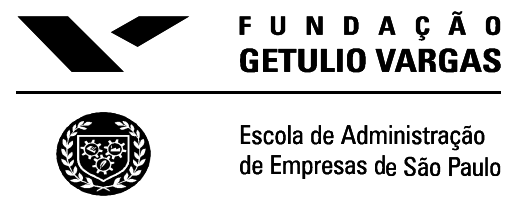




\title{
RESUMO
}

Este estudo objetiva analisar os efeitos da primeira fase da transição para o IFRS (International Financial Reporting Standard) no Brasil, a partir de 2008 (Lei 11.638/07), nos resultados das empresas listadas na Bovespa (Bolsa de Valores de São Paulo). Aplicou-se o inverso do Índice de Conservadorismo de Gray $(1980,1988)$ a amostras gradativamente reduzidas conforme a transparência e compliance com a nova norma. Foram verificados resultados pela nova norma em média superiores aos apurados pela norma anterior, confirmando o conservadorismo contábil brasileiro previsto por Gray. Certas inconsistências entre 2007 e 2008 foram relacionadas aos impactos da crise financeira global de 2008 em ajustes específicos aos resultados.

PALAVRAS-CHAVE Harmonização internacional, IFRS, BR GAAP, Lei 11.638, índice de conservadorismo.

\begin{abstract}
This study aims to analyze the effects of the initial transition to IFRS (International Financial Reporting Standard) in Brazil, beginning 2008 (Law 11.638/07), on results of companies listed in Bovespa (Bolsa de Valores de São Paulo). The inverse of Gray's (1980, 1988) Index of Conservatism was applied to gradually reduced samples as per transparence and compliance with the new norm. Higher average results measured by new norm than by the prior norm were found - thus indicating Brazilian accounting conservatism, as predicted by Gray. Some inconsistencies between 2007 and 2008 were linked to impacts of the 2008 global financial crisis on specific adjustments to results.
\end{abstract}

KEYWORDS International accounting harmonization, IFRS, BR GAAP, Law 11.638, conservatism index.

\section{RESUMEN}

Este estudio tiene como objetivo analizar los efectos de la primera fase de la transición al IFRS (International Financial Reporting Standard) en Brasil, a partir de 2008 (Ley 11.638/07), en los resultados de las empresas listadas en la Bovespa (Bolsa de Valores de São Paulo). Se aplicó el inverso del Índice de Conservadorismo de Gray (1980, 1988) a muestras gradualmente reducidas, conforme la transparencia y compliance con la nueva norma. La nueva norma verificó resultados superiores en promedio a los verificados por la norma anterior, lo que confirma el conservadorismo contable brasileño previsto por Gray. Ciertas inconsistencias entre 2007 y 2008 fueron relacionadas a los impactos de la crisis financiera global de 2008 en ajustes específicos a los resultados.

PALABRAS CLAVE Armonización internacional, IFRS, BR GAAP, Ley 11.638, índice de conservadorismo. 


\section{INTRODUÇÃO}

Após anos de deliberação, a Lei 11.638/07 determinou a harmonização contábil com o IFRS (International Financial Reporting Standard), alinhando o Brasil ao processo de internacionalização da contabilidade, atualmente em curso em mais de 100 países.

Contrapondo-se à tradição formalista brasileira, o fundamento consuetudinário do padrão IFRS, ao priorizar a essência sobre a forma, o julgamento da realidade econômica sobre a mera desincumbência normativa e a transparência para o investidor, certamente representará profunda transformação na contabilidade, no perfil de seus profissionais e em seu currículo disciplinar.

A percepção dessa transformação provocou turbulências no mercado. Contadores e controllers viram sua discreta atividade figurar subitamente como "revolucionária" na imprensa (NIERO, 2008), em meio a discussões sobre os impactos da nova lei. Sua publicação em Diário Oficial extra no último dia útil de 2007, com implicações já para os dias seguintes, fez Nelson Carvalho comentar: "Tivemos três dias para fazer o que a Europa fez em cinco anos" (NIERO e outros, 2009). Em sucessivas regulamentações para adoção inicial da lei, catorze pronunciamentos do CPC (Comitê de Pronunciamentos Contábeis), alguns bastante inovadores, foram discutidos e publicados em 2008. Só em 03/12/2008 foi confirmada a "neutralidade fiscal" das novas normas, com a Medida Provisória $\mathrm{n}^{\circ}$ 449. As normas finais da adoção inicial da lei (CPC 13, Deliberação CVM 565) para o exercício de 2008 foram publicadas apenas em 17/12/2008. Nesse ambiente, os primeiros balanços ensejaram notícias de "ajustes milionários", com aumento ou diminuição dos lucros contábeis apurados segundo a nova norma (VALENTI e FREGONI, 2008, BIANCONI, 2009).

O interesse pelos impactos do IFRS reflete a expectativa de que sua adoção no Brasil, tal como ocorre em outros países, trará para as empresas benefícios de liquidez, menor custo de capital e maior valorização e atratividade no mercado, como notam Schroeder e outros (2001, p. 175): "If investors and creditors cannot obtain understandable financial information about companies that operate in foreign countries, they are not likely to invest in or lend money to these companies". Inaugura-se, com efeito, uma competição global pela melhor informação: "One of the major problems currently facing U.S. corporations is their ability to compete in a global economy with transnational financial reporting" (id, ibidem).

Assim, para analistas, investidores, reguladores e agentes do mercado, é relevante identificar na atual transição tanto as diferenças normativas (de jure), como os graus de transparência e compliance 
das empresas (diferenças de facto), com vista a mensurar os efeitos da nova norma nos resultados reportados.

O problema aqui pesquisado pode ser assim definido: qual o impacto da Lei $11.638 / 07$, em particular das primeiras normas de transição para o IFRS (CPC 13), nos resultados de 2008 e republicações de 2007, reportados pelas companhias abertas brasileiras em 2009, como primeiros relatórios no novo padrão contábil?

O objetivo deste estudo é mensurar o impacto da adoção inicial da Lei 11.638/07, regulada pelo CPC 13, nos resultados das companhias listadas na Bovespa (Bolsa de Valores de São Paulo). Assim, esta pesquisa pode ser caracterizada como empírico-analítica descritiva, baseada em dados secundários publicados nas DFPs (Demonstrações Financeiras Padronizadas) de 2008.

Para análise das diferenças no lucro apurado conforme sistemas contábeis diversos, Gray (1980, 1988) propôs o Índice de Conservadorismo, prevendo que sistemas contábeis de tradição eurocontinental, como o do Brasil, tendem a apresentar lucros menores diante dos sistemas de influência anglo-americana, como são os US GAAP e o IFRS, o que outros estudos têm confirmado.

Assim, uma hipótese deste trabalho é que a primeira fase de transição para o IFRS no Brasil tenderá a gerar resultados superiores aos apurados pela norma brasileira anterior.

\section{REVISÃO DA LITERATURA}

Uma breve abordagem das razões socioculturais das diferenças entre sistemas contábeis ressalta a relevância das principais mudanças introduzidas pela nova lei na contabilidade brasileira e de seus impactos nos resultados reportados pelas empresas.

\section{Cultura contábil e o Índice de Comparabilidade}

No final do século XX, a competição no mercado internacional de capitais, em particular a emissão de ADRs (American Depositary Receipts), obrigando a duplas demonstrações contábeis, tornou relevante investigar o quanto e por que uma norma nacional gera resultados diferentes dos mensurados por outra norma. Gray (1980 e 1988), Radebaugh e outros (2006), Ding e outros (2005), Nobes e Parker (2006) e Saudagaran (2001), entre outros, estudam as razões socioculturais dessas diferenças. Assim, os países de influência anglo-americana enfatizam o direito consuetudinário (common law); a ética individual do mérito; o Estado pouco invasivo; o mercado de capitais sólido; a profissão contábil reconhecida e 
atuante; e demonstrações contábeis com foco nos investidores. Já o modelo eurocontinental (Alemanha, Bélgica, Espanha, França, Itália, Japão, países da América do Sul) ressalta o direito formalista (code law); o corporativismo; maior interferência do Estado na contabilidade com objetivos fiscais; a profissão contábil pouco reconhecida; a predominância de financiamento bancário ou familiar sobre o mercado de capitais; e demonstrações contábeis voltadas mais para credores e fisco (ver também NIYAMA, 2005).

Partindo de um estudo de Hofstede (1980) sobre o impacto de elementos culturais no comportamento em multinacionais de mais de 50 países, Gray (1988) definiu quatro accounting values, que expressam as origens socioculturais das diferenças entre os sistemas contábeis dos diversos países:

- profissionalismo x controle estatutário: grau de exercício do julgamento profissional, independência e self-regulation da profissão contábil versus grau de submissão a exigências legais prescritivas e controle estatutário;

- uniformidade x flexibilidade: uniformidade de práticas entre as empresas e consistência ao longo do tempo versus flexibilidade em relação a circunstâncias específicas de empresas individuais;

- conservadorismo x otimismo: abordagem de precaução na mensuração, avessa ao risco versus abordagem laissez-faire, tomadora de risco;

- segredo x transparência: confidencialidade e informação apenas aos diretamente envolvidos na gestão e financiamento versus transparência, abertura e disponibilidade pública das informações.

Nesse trabalho, Gray classifica o Brasil entre os países latinos mais desenvolvidos (juntamente com França, Itália, Espanha e Argentina), os quais, em comparação com países de influência angloamericana, se caracterizam por um menor espaço para julgamento do profissional no exercício da contabilidade, um maior formalismo e uniformidade na aplicação das normas, pouca transparência nas informações e um maior grau de conservadorismo na mensuração do resultado. Mais especificamente, o conservadorismo na mensuração do lucro decorreria de uma contabilidade mais voltada para o fisco nesses países, ao contrário da ênfase no investidor em países de influência anglo-americana, nos quais se desvincula a contabilidade para o investidor da contabilidade para o fisco.

Como metodologia quantitativa para expressar o impacto dessas influências culturais e institucionais no resultado reportado pelas empresas, Gray (1980) propôs o Índice de Conservadorismo, que mensura o quanto lucros menores (conservadorismo, verificado na França e Alemanha) ou maiores 
(otimismo, verificado na Inglaterra) eram demonstrados pelos sistemas contábeis locais em relação ao padrão do European Method. Weetman e outros (1998) renomearam o índice de Gray como Índice de Comparabilidade total (IC, referente ao todo do resultado) ou parcial (ICP, referente a cada ajuste específico), em comparação com os US GAAP (US Generally Accepted Accouting Principles) ou com as normas do IAS (International Accounting Standards), quando for o caso.

Nas equações (1) e (1A), um IC/ICP menor que 1 denota conservadorismo (lucros/ajustes locais menores em relação aos US GAAP) e, vice-versa, um IC/ICP maior que 1 indica otimismo (lucros/ajustes locais superiores aos apurados pelos US GAAP).

$$
I C=1-\left[\frac{\text { Lucro }_{U S A}-\text { Lucro }_{\text {Local }}}{\mid \text { Lucro }_{U S A} \mid}\right]
$$

$$
I C P=1-\frac{\text { Ajuste Parcial }}{\mid \text { Lucro }_{U S A} \mid}
$$

A metodologia de Gray tem sido utilizada em numerosos trabalhos sobre diferenças entre os US GAAP e sistemas contábeis nacionais, como: Inglaterra (WEETMAN e GRAY, 1990); Finlândia (ADAMS e outros, 1993); Suécia (HELLMAN, 1993); Austrália (NORTON, 1995); Japão (COOKE, 1993); Inglaterra, Suécia e Holanda (WEETMAN e GRAY, 1991); Brasil, Argentina, Chile e México (SANTOS e outros, 2008), entre outros.

Desde antes da adoção obrigatória do IFRS na Europa (2005), o Índice de Comparabilidade tem baseado comparações entre o padrão internacional e normas nacionais.

Estudando empresas da Alemanha que entre 1995-2002 optaram por apresentar demonstrações conforme padrões internacionalmente aceitos (US GAAP ou IAS/IFRS), Beckman e outros (2007) identificam o conservadorismo básico (tendência a expressar lucros e PL menores) do tradicional Código Comercial Alemão (HGB - Handelsgesetzbuch) em relação tanto ao IFRS (IC = -4,21 para o lucro e = 0,93 para PL) como aos US GAAP $(\mathrm{IC}=0,64$ para o lucro e $=0,82$ para o PL).

O’Connell e Sullivan (2008) estudam o impacto no resultado de 37 empresas first time implementers do IFRS em 2004, pertencentes a países eurocontinentais (os autores utilizam o inverso do índice original de Gray/Weetman). Assim, foram obtidos $\mathrm{IC}^{-1}$ médios de: $0,80(\mathrm{IC}=1,25)$ para Alemanha, 1,13 (IC = 0,88) para Espanha, 1,40 (IC = 0,71) para França, 1,11 (IC = 0,90) para Itália, e 1,21 (IC $=0,83)$ para Holanda, confirmando o conservadorismo contábil desses países. Os autores notam que a adoção anterior de padrões internacionais na Alemanha teria atenuado o impacto inicial do IFRS. 
Cordazzo (2007) evidencia o conservadorismo contábil em empresas listadas na Borsa Italiana em 2006, que demonstraram lucro líquido 12,47\% menor e patrimônio líquido 4,78\% inferior aos mensurados conforme o IFRS.

Poucos estudos comparam os lucros apurados no sistema contábil brasileiro com padrões internacionais. Doupnik e Riccio (2006) focam os conceitos de conservadorismo e segredo de Gray (1988) para investigar a influência cultural no julgamento, por profissionais brasileiros e americanos, de expressões utilizadas pelo IFRS, que impliquem maior ou menor reconhecimento de lucro, tendo obtido suporte para a confirmação do conservadorismo brasileiro. Alguns trabalhos aplicam o Índice de Conservadorismo de Gray (1980) para comparar os US GAAP com as normas brasileiras em emissoras de ADRs. Lemes e outros (2007) estudam a comparabilidade dos resultados entre os dois padrões. Santos e outros (2007) e Santos e Cia (2008) confirmam o conservadorismo do lucro na contabilidade brasileira no período 2003-2006 em relação aos US GAAP. Tomando os US GAAP como proxy do IFRS, este último estudo estima que a harmonização internacional levaria a "um novo patamar de lucro, aproximadamente $15 \%$ superior ao atual".

\section{Principais mudanças introduzidas pelas Leis 11.638/07 e 11.941/09 (MP 449/08)}

Após a aprovação da nova Lei das S/As, a CVM (2008), no processo de regulação, optou por uma harmonização gradativa com o padrão internacional no Brasil, emitindo um conjunto de normas para a fase de "adoção inicial" em 2008 (ver CPC 13), e projetando uma fase posterior de "integral convergência" para o full IFRS em 2010. O Quadro 1 contrapõe sinteticamente as normas anteriores às mudanças determinadas pelo CPC e CVM para o exercício de 2008.

Quadro 1 - Principais Mudanças Introduzidas pelas leis 11.638/07 e 11.941/09 (MP 449/08)

\begin{tabular}{|l|l|l|l|}
\hline Item & $\begin{array}{l}\text { IASB, CPC e } \\
\text { Delib. CVM }\end{array}$ & $\begin{array}{l}\text { Normas anteriores } \\
\text { (Lei 6.404/76 e Deliberações da CVM) }\end{array}$ & $\begin{array}{l}\text { Normas atuais (Lei 11.638/07, MP } \\
\text { 449/08 e Deliberações da CVM) } \\
\text { Mudanças com efeito potencial no } \\
\text { Resultado e/ou Patrimônio Líquido }\end{array}$ \\
\hline $\begin{array}{l}\text { Instrumentos } \\
\begin{array}{l}\text { Financeiros } \\
\text { (Fase 1) }\end{array}\end{array}$ & $\begin{array}{l}\text { IAS 32, 39 e } \\
\text { IFRS 7 } \\
\text { (partes) } \\
\text { CPC 14 } \\
\text { Delib. CVM } \\
566 / 08\end{array}$ & $\begin{array}{l}\text { Reconhecidos pelo custo amortizado. } \\
\text { No caso de títulos de renda fixa, os juros } \\
\text { eram calculados pela taxa nominal. }\end{array}$ & $\begin{array}{l}\text { Requer o reconhecimento e mensuração } \\
\text { pelo valor justo de certos instrumentos } \\
\text { financeiros e derivativos, como segue: } \\
\text { 1. Mantidos para Negociação: } \\
\text { mensurados ao valor justo por meio } \\
\text { do resultado. }\end{array}$ \\
& $\begin{array}{l}\text { 2. Disponíveis para Venda: diferenças } \\
\text { entre o valor justo e o valor contábil } \\
\text { lançadas na conta Ajuste de Avaliação } \\
\text { Patrimonial, no Patrimônio Líquido. } \\
\text { 3antidos até o Vencimento: avaliados }\end{array}$ \\
\hline
\end{tabular}




\begin{tabular}{|c|c|c|c|}
\hline & & & $\begin{array}{l}\text { ao custo amortizado, mas com juros } \\
\text { calculados pela taxa efetiva. }\end{array}$ \\
\hline $\begin{array}{l}\text { Operações de } \\
\text { Arrendamento } \\
\text { Mercantil }\end{array}$ & $\begin{array}{l}\text { IAS } 17 \\
\text { CPC } 06 \\
\text { Delib. CVM } \\
554 / 08\end{array}$ & $\begin{array}{l}\text { Sem distinção entre leasing operacional } \\
\text { e financeiro, sendo todos tratados como } \\
\text { operacionais. } \\
\text { Na arrendatária: prestação do leasing } \\
\text { lançada integralmente como despesa, } \\
\text { quando incorrida. } \\
\text { Na arrendadora: o bem arrendado ficava } \\
\text { no Imobilizado e era depreciado. A } \\
\text { prestação do leasing era lançada } \\
\text { integralmente como receita. }\end{array}$ & $\begin{array}{l}\text { Requer que itens objeto de contratos que } \\
\text { apresentem características de } \\
\text { arrendamento mercantil financeiro sejam } \\
\text { contabilizados como ativo da arrendatária. } \\
\text { Na arrendatária: contabilização como } \\
\text { compra financiada. A despesa com leasing } \\
\text { é substituída pela depreciação do ativo } \\
\text { mais os juros. } \\
\text { Na arrendadora: contabilização como } \\
\text { venda financiada. O resultado da venda } \\
\text { afeta o lucro no momento da venda. } \\
\text { Durante o prazo do contrato são } \\
\text { reconhecidos apenas os juros. }\end{array}$ \\
\hline $\begin{array}{l}\text { Ativo Intangível e } \\
\text { Ativo Diferido }\end{array}$ & $\begin{array}{l}\text { IAS } 38 \\
\text { CPC 04 } \\
\text { Delib. CVM } \\
\text { 553/08 }\end{array}$ & $\begin{array}{l}\text { Era permitida a capitalização de algumas } \\
\text { despesas, como despesas pré- } \\
\text { operacionais, gastos com reestruturação, } \\
\text { pesquisa e desenvolvimento, alguns } \\
\text { tipos de gastos com publicidade e } \\
\text { propaganda e treinamento. } \\
\text { Não havia o grupo ativo Intangível e o } \\
\text { ágio na combinação de negócios e } \\
\text { outros intangíveis era classificado como } \\
\text { ativo Diferido. }\end{array}$ & $\begin{array}{l}\text { Extingue o grupo Ativo Diferido e cria o } \\
\text { grupo Ativo Intangível. } \\
\text { Proíbe a capitalização de praticamente } \\
\text { todas as despesas antes passíveis de serem } \\
\text { lançadas no Diferido, lançando-as agora } \\
\text { contra o resultado. } \\
\text { Cria uma série de exigências para } \\
\text { reconhecimento de ativos intangíveis } \\
\text { desenvolvidos internamente. } \\
\text { Saldos anteriores de Ativos Diferidos } \\
\text { podem ser baixados integralmente na data } \\
\text { de transição ou continuar a ser } \\
\text { amortizados pelo prazo remanescente. }\end{array}$ \\
\hline $\begin{array}{l}\text { Redução de ativos } \\
\text { ao Valor } \\
\text { recuperável } \\
\text { (impearment) }\end{array}$ & \begin{tabular}{|l} 
IAS 36 \\
CPC 01 \\
Delib. CVM \\
$527 / 07$
\end{tabular} & Não previsto & $\begin{array}{l}\text { Institui a exigência de se fazerem testes } \\
\text { regulares de impairment para verificar a } \\
\text { necessidade de reduzir ativos ao seu valor } \\
\text { recuperável, com reconhecimento de perda } \\
\text { no resultado. }\end{array}$ \\
\hline $\begin{array}{l}\text { Ajuste a Valor } \\
\text { Presente }\end{array}$ & $\begin{array}{l}\text { IASB: NA } \\
\text { CPC 12 } \\
\text { Delib. CVM } \\
\text { 564/08 }\end{array}$ & Não previsto & $\begin{array}{l}\text { Institui a exigência de se fazerem ajustes a } \\
\text { valor presente de elementos integrantes do } \\
\text { ativo e passivo decorrentes de operações } \\
\text { de longo prazo, ou de curto prazo, quando } \\
\text { houver efeitos relevantes. } \\
\text { O ajuste a valor presente deve ser efetuado } \\
\text { na data de origem da transação, utilizando- } \\
\text { se a taxa contratual ou implícita. Na } \\
\text { constituição, o ajuste pode ter como } \\
\text { contrapartida um ativo, despesa ou receita; } \\
\text { as reversões terão contrapartida em receita } \\
\text { ou despesa (em geral) financeira. }\end{array}$ \\
\hline $\begin{array}{l}\text { Equivalência } \\
\text { Patrimonial }\end{array}$ & $\begin{array}{l}\text { IAS } 28 \\
\text { Instr. CVM } \\
469 / 08\end{array}$ & $\begin{array}{l}\text { São avaliados por equivalência } \\
\text { patrimonial os investimentos relevantes } \\
\text { em coligadas ou equiparadas em que a } \\
\text { administração tenha influência } \\
\text { significativa ou de que participe com } \\
20 \% \text { ou mais do capital, bem como em } \\
\text { controladas ou que façam parte de um } \\
\text { mesmo grupo ou estejam sob controle } \\
\text { comum. }\end{array}$ & $\begin{array}{l}\text { São avaliados por equivalência } \\
\text { patrimonial os investimentos em } \\
\text { sociedades em que a administração tenha } \\
\text { influência significativa, ou nas quais } \\
\text { participe com } 20 \% \text { ou mais do capital } \\
\text { votante, ou que façam parte de um mesmo } \\
\text { grupo ou estejam sob controle comum. } \\
\text { Muda o conceito de coligada e, ao eliminar } \\
\text { o teste de relevância dos investimentos, } \\
\text { amplia o alcance da aplicação do método }\end{array}$ \\
\hline
\end{tabular}




\begin{tabular}{|c|c|c|c|}
\hline & & & $\begin{array}{l}\text { de equivalência patrimonial, com efeito no } \\
\text { resultado. }\end{array}$ \\
\hline $\begin{array}{l}\text { Custos de } \\
\text { Transação e } \\
\text { Prêmios na } \\
\text { Emissão de } \\
\text { Títulos }\end{array}$ & $\begin{array}{l}\text { IAS } 39 \\
\text { (partes) } \\
\text { CPC 08 } \\
\text { Delib. CVM } \\
\text { 556/08 }\end{array}$ & $\begin{array}{l}\text { Os custos de transação na emissão de } \\
\text { títulos eram lançados no resultado. } \\
\text { Os prêmios na emissão de debêntures } \\
\text { eram antes lançados na conta Reserva de } \\
\text { Capital, no Patrimônio Líquido. }\end{array}$ & $\begin{array}{l}\text { Os custos de transação na emissão de } \\
\text { títulos patrimoniais são lançados como } \\
\text { conta redutora no Patrimônio Líquido. } \\
\text { Os títulos de dívida emitidos são } \\
\text { contabilizados pelo valor líquido } \\
\text { disponibilizado pela transação. Assim, os } \\
\text { custos de transação, prêmios e outros são } \\
\text { lançados no resultado pela apropriação da } \\
\text { taxa efetiva (TIR). }\end{array}$ \\
\hline $\begin{array}{l}\text { Subvenções e } \\
\text { Assistências } \\
\text { Governamentais }\end{array}$ & $\begin{array}{l}\text { IAS } 20 \\
\text { CPC } 07 \\
\text { Delib. CVM } \\
\text { 555/08 }\end{array}$ & $\begin{array}{l}\text { Reconhecidos anteriormente no } \\
\text { Patrimônio Líquido, como Reserva de } \\
\text { Capital. }\end{array}$ & Reconhecidos como receita no resultado. \\
\hline $\begin{array}{l}\text { Reavaliação de } \\
\text { ativos }\end{array}$ & \begin{tabular}{|l|} 
IAS 16 e 38 \\
Lei \\
$11.638 / 07$
\end{tabular} & $\begin{array}{l}\text { A reavaliação era permitida no Brasil } \\
\text { apenas para o ativo imobilizado. } \\
\text { Pelas IFRSs a reavaliação é permitida, } \\
\text { inclusive para ativos intangíveis. }\end{array}$ & $\begin{array}{l}\text { Proíbe novas reavaliações. Os saldos } \\
\text { anteriores podem ser revertidos ou } \\
\text { depreciados até que o ativo se extinga ou } \\
\text { seja vendido. } \\
\text { Aumenta o resultado pela exclusão do seu } \\
\text { efeito na depreciação. } \\
\text { Contraria o IAS } 16 \text { e } 38 \text {. }\end{array}$ \\
\hline $\begin{array}{l}\text { Pagamentos } \\
\text { baseados em } \\
\text { ações }\end{array}$ & \begin{tabular}{|l|} 
IFRS 2 \\
CPC 10 \\
Delib. CVM \\
$562 / 08$
\end{tabular} & $\begin{array}{l}\text { A remuneração baseada em ações só era } \\
\text { reconhecida no resultado quando a } \\
\text { opção fosse exercida. }\end{array}$ & $\begin{array}{l}\text { Institui o reconhecimento como despesa } \\
\text { ou participações as remunerações baseadas } \\
\text { em ações liquidadas com instrumentos } \\
\text { patrimoniais (ações ou opções de compra } \\
\text { de ações), mensuradas pelo valor justo, no } \\
\text { momento em que são outorgados, em } \\
\text { contrapartida da conta Ações/Opções } \\
\text { Outorgadas, no Patrimônio Líquido. }\end{array}$ \\
\hline $\begin{array}{l}\text { Efeitos das } \\
\text { Mudanças nas } \\
\text { Taxas de Câmbio } \\
\text { e Conversão de } \\
\text { Demonstrações } \\
\text { Contábeis }\end{array}$ & $\begin{array}{l}\text { IAS } 21 \\
\text { CPC } 02 \\
\text { Delib. CVM } \\
534 / 08\end{array}$ & $\begin{array}{l}\text { Semelhante ao definido atualmente, } \\
\text { exceto no que se refere à maior } \\
\text { aplicação do Real como moeda } \\
\text { funcional. }\end{array}$ & $\begin{array}{l}\text { A moeda funcional de subsidiárias de } \\
\text { empresas brasileiras no exterior deve ser o } \\
\text { Real, a menos que essas subsidiárias } \\
\text { constituam, em essência, unidade } \\
\text { autônoma. } \\
\text { Potencialmente, empresas que utilizavam o } \\
\text { dólar como moeda funcional tenderão a } \\
\text { substituí-lo pelo Real, mudando o método } \\
\text { de conversão das demonstrações contábeis, } \\
\text { com efeitos no resultado. }\end{array}$ \\
\hline $\begin{array}{l}\text { Adoção inicial da } \\
\text { Lei 11.638/07 }\end{array}$ & \begin{tabular}{|l|} 
CPC 13 \\
Delib. CVM \\
565/08
\end{tabular} & Não se aplica & $\begin{array}{l}\text { Regula as primeiras demonstrações } \\
\text { contábeis (adoção inicial) a serem } \\
\text { elaboradas aplicando as novas práticas } \\
\text { contábeis no Brasil em atendimento à Lei } \\
11.638 / 07 \text { e MP } 449 / 08 \text {. }\end{array}$ \\
\hline
\end{tabular}

\section{MÉTODO}

Para identificar o impacto da adoção inicial da nova lei no Lucro Líquido (LL) e Patrimônio Líquido (PL) das empresas, foram tomadas as Demonstrações Financeiras Padronizadas (DFPs) de 2008, publicadas pelas empresas listadas na Bovespa (nos segmentos tradicional, nível 1, nível 2 e Novo 
Mercado), que as disponibilizaram no sistema da CVM até 10 dias após o encerramento do prazo regulamentar (10/04/2009). Para essas empresas, foram coletadas também as DFPs de 2007. Para evitar distorções, foram excluídas: as instituições financeiras - que já aplicavam anteriormente várias das novas normas, por determinação do Banco Central; as empresas com data de encerramento diferente de 31/12; e as que não disponibilizaram DFPs nos dois anos analisados.

Os dados foram coletados das Notas Explicativas (NEs) das DFPs de 2008. Para possibilitar a comparação do impacto de cada ajuste no LL e PL das empresas, os ajustes informados nas NEs foram classificados em 13 grupos.

O segmento de listagem e o setor de atuação das empresas foram coletados do site da Bovespa. A informação sobre as emissoras brasileiras de ADRs foi obtida no site da NYSE.

Para mensurar o impacto da nova lei no LL e PL das empresas foi utilizado o inverso do já mencionado Índice de Comparabilidade, tomando-se por base a norma brasileira anterior (Lei 6.404/76), conforme a seguinte fórmula:

$$
I C^{-1}=1-\left[\frac{\text { Lucro }_{\text {Lei 6.404 }}-\text { Lucro }_{\text {Lei 11.638 }}}{\mid \text { Lucro }_{\text {Lei 6. 604 }} \mid}\right]=1+\left[\frac{\text { Lucro }_{\text {Lei 11.638 }}-\text { Lucro }_{\text {Lei 6.404 }}}{\mid \text { Lucro }_{\text {Lei 6. } 604} \mid}\right]
$$

Onde:

$I C^{-1}=$ Índice de Comparabilidade Inverso (ICI).

Lucro $_{\text {Lei. } 6.407}=$ Lucro Líquido (ou prejuízo) apurado conforme as normas vigentes até 2007 (Lei 6.404/76 e respectivas normas da $\mathrm{CVM}$ ).

Lucro $_{\text {Lei.11.638 }}=$ Lucro Líquido (ou prejuízo) apurado conforme as normas vigentes a partir de 2008 (Lei $11.638 / 07$ e respectivas normas da CVM).

A partir da equação (2), a hipótese deste trabalho pode ser assim formulada:

$\mathbf{H}_{\mathbf{0}}$ : ICI $\leq 1$ (a norma de transição para o IFRS gera resultados menores que a norma anterior).

$\mathbf{H}_{1}$ : ICI >1 (a norma de transição para o IFRS gera resultados maiores que a norma anterior).

A utilização do inverso desses índices, também adotada por outros autores como Cordazzo (2007), possibilita tornar a análise mais intuitiva, tomando como base a norma antiga (aumentos de resultados geram valores maiores que 1 e vice-versa, ao contrário dos índices originais).

Como notam Weetman e outros (1998), o Índice de Comparabilidade (IC) tende a resultados extremos quando o denominador tende a zero, o que enseja neste trabalho especial atenção a outliers. 


\title{
ANÁLISE DOS RESULTADOS
}

Conforme as formas ou graus observados de transparência e compliance das empresas com as novas normas, o exame comparativo dos resultados abordou primeiramente as empresas que publicaram nas NEs a Tabela de Reconciliação do Resultado e a seguir, num maior refinamento, as empresas que publicaram a reconciliação em ambos os exercícios, 2007 e 2008.

\section{Transparência e compliance com as normas de adoção inicial da nova lei}

Para a adoção inicial do IFRS, o CPC 13, por um lado, enfatiza o princípio geral de transparência, que obriga uma republicação da demonstração do período anterior conforme a nova norma, para fins de comparação, mas, por outro, atenua essa obrigação, ao determinar:

\begin{abstract}
A norma sobre "Práticas Contábeis, Mudanças nas Estimativas Contábeis e Correção de Erros" requer que, além de discriminar os efeitos da adoção da nova prática contábil na conta de lucros ou prejuízos acumulados, a entidade deve demonstrar o balanço de abertura para cada conta ou grupo de contas relativo ao período mais antigo apresentado para fins de comparação, bem como os demais valores comparativos apresentados, como se a nova prática contábil estivesse sempre em uso. Todavia, para fins da aplicação inicial da Lei $n^{\circ}$. 11.638/07 e Medida Provisória ${ }^{\circ}$ 449/08, este pronunciamento desobriga as entidades quanto à aplicação dessa norma, ou seja, ao aplicar a lei pela primeira vez, as entidades são requeridas apenas a aplicar o $\S 1^{\circ}$ do art. 186 [da Lei 6.404/76]. (CPC 13, §3).
\end{abstract}

Assim, embora não obrigando a republicação das demonstrações de 2007 pela nova norma, e priorizando a facilidade para as empresas em detrimento da comparabilidade e transparência para o investidor, o CPC 13 ( $\$$ 56, item b), determina a apresentação em NE da demonstração dos efeitos das práticas contábeis modificadas no resultado e no PL. Desse modo, no início da adoção da Lei 11.638, as empresas:

1. estão obrigadas a contabilizar os ajustes iniciais na conta de Lucros ou Prejuízos Acumulados ( $\S 1^{\circ}$ do art. 186 da Lei 6.404/76); 
2. estão obrigadas a apresentar nas NEs os efeitos da nova lei no resultado e no PL (CPC 13, § $56, \mathrm{~b})$;

3. ficam desobrigadas de reapresentar as demonstrações de 2007 com base nas normas de 2008.

Ao mesmo tempo, no $\S 10$, o mesmo CPC esclarece que as empresas que optarem por reapresentar as demonstrações de 2007 terão 01/01/2007 como data de transição para a nova norma. Para as demais empresas, a data de transição fica fixada em 01/01/2008.

Diante dessas determinações e da flexibilização da norma, seria de esperar que todas as empresas apresentassem os ajustes iniciais na DMPL, bem como divulgassem nas NEs os efeitos da nova lei no resultado. Tal, entretanto, não ocorreu, como se evidencia na Tabela 1.

A Tabela 1 apresenta o grau de compliance com o CPC 13, em relação a três aspectos principais: declaração em NE se houve ou não efeito da nova lei no resultado; informação da data de transição para as novas normas adotada pela empresa; e a forma escolhida para a divulgação do efeito da adoção inicial. A grande maioria das empresas (232, ou 73\%) declarou em NE que a adoção da Lei 11.638/07 e MP 449/08 gerou efeito no seu resultado, mas 83 empresas (26\%) declararam não ter havido efeito. E $10 \%$ das empresas analisadas ou não declararam a data de transição adotada (28 empresas) ou declararam uma data diferente (três empresas) das duas opções determinadas pelo CPC 13.

A desobrigação de reapresentação das demonstrações de 2007 suscitou, com variada transparência, diversas formas de disclosure do efeito da adoção inicial da nova lei. Observa-se, primeiramente, que 87 empresas (27\%) declararam ter havido efeito no resultado, mas não apresentaram o ajuste inicial na DMPL, contrariando, assim, a norma. Das empresas estudadas (após exclusões por inconsistências), 175 (55\% do total e 75\% das que declararam efeitos) apresentaram nas NEs a tabela de reconciliação dos efeitos da lei em pelo menos um dos exercícios. No que significaria um maior grau de transparência, somente 89 empresas (28\%) reapresentaram as demonstrações financeiras de 2007 com base nas novas normas. Já quanto ao critério da mais ampla divulgação dos efeitos da nova lei, apenas 34 empresas (11\%) publicaram a tabela de reconciliação, mostrando os efeitos da nova lei em ambos os exercícios, de 2007 e de 2008.

Alguns desses dados causam certa estranheza: embora 89 empresas tenham realizado o mais difícil (reapresentar os balanços de 2007), apenas 34 divulgaram em NE a tabela de reconciliação do efeito da lei no resultado e PL dos dois anos, ou seja, a maioria das 89 empresas não mostrou os efeitos da lei nos números de 2008. Ora, essa informação, além de não ter praticamente custo adicional para 
essas empresas, teria sido de grande relevância para o investidor, dado que o exercício de 2007 já era pretérito e 2008 é efetivamente o primeiro ano de vigência das novas normas. Além disso, para o pesquisador, a análise fica prejudicada, pois a indisponibilidade desses dados de 2008 faz com que não exista um só exercício em que todas as empresas tenham publicado os efeitos da nova lei.

Tabela 1 - Compliance com a norma e transparência na adoção inicial da Lei (CPC 13)

\begin{tabular}{|c|c|c|}
\hline & Fi & $\%$ \\
\hline Total de empresas listadas na Bovespa, exceto Instituições Financeiras & 318 & $100 \%$ \\
\hline \multicolumn{3}{|l|}{ Declaração em Nota Explicativa se houve efeito } \\
\hline Empresas que declararam não ter ocorrido efeito & 83 & $26 \%$ \\
\hline Empresas que não indicaram se houve efeito & 3 & $1 \%$ \\
\hline Empresas que declararam ter ocorrido efeito & 232 & $73 \%$ \\
\hline \multicolumn{3}{|l|}{ Data de transição para a nova lei } \\
\hline Declararam data de transiçãa 01/01/2007 & 81 & $25 \%$ \\
\hline Declararam data de transicão $01 / 01 / 2008$ & 206 & $65 \%$ \\
\hline Não declararam a data de transição & 28 & $9 \%$ \\
\hline Declararam outras datas de transição & 3 & $1 \%$ \\
\hline \multicolumn{3}{|l|}{ Formas de divulgação do efeito da adoção inicial da Lei } \\
\hline $\begin{array}{l}\text { Empresas que tiveram efeito no resultado, mas não apresentaram o ajuste } \\
\text { na DMPL }\end{array}$ & 87 & $27 \%$ \\
\hline $\begin{array}{l}\text { Apresentaram nas NEs a tabela de reconciliação dos efeitos da Lei em } \\
\text { pelo menos um dos exercícios }\end{array}$ & 175 & $55 \%$ \\
\hline $\begin{array}{l}\text { Reapresentaram } 2007 \text { conforme as novas normas para fins de } \\
\text { comparacão }\end{array}$ & 89 & $28 \%$ \\
\hline $\begin{array}{l}\text { Apresentaram nas NEs a tabela de reconciliação dos efeitos da Lei tanto } \\
\text { no exercício de } 2007 \text { como no de } 2008\end{array}$ & 34 & $11 \%$ \\
\hline
\end{tabular}

Outra verificação surpreendente é a transparência, menor que a esperada, em empresas de segmentos especiais de listagem da Bovespa, bem como de emissoras de ADRs na NYSE. Pela Tabela 2 observa-se que, das 25 empresas brasileiras com ADRs negociadas na bolsa norte-americana que declararam que a nova lei gerou efeito nos seus números, apenas 17 (68\%) adotaram a forma de divulgação mais transparente. Esperava-se uma ocorrência de 100\%, já que essas empresas apresentam normalmente suas demonstrações à SEC conforme os US GAAP (que são bem mais complexos e completos que as normas de adoção inicial exigidas pelo CPC 13). A situação é mais problemática diante da expectativa de maior transparência das empresas listadas no novo mercado, pois apenas $41 \%$ das empresas que declaram ter havido efeito da nova norma no resultado, reapresentaram os balanços de 2007 e, além disso, apenas 18\% divulgaram a reconciliação dos efeitos também em 2008. 
Tabela 2 - Transparência: empresas do novo mercado e emissoras de ADRs na NYSE

\begin{tabular}{|c|c|c|c|c|}
\hline & \multicolumn{2}{|c|}{$\begin{array}{c}\text { Novo } \\
\text { Mercado }\end{array}$} & \multicolumn{2}{|c|}{$\begin{array}{l}\text { ADRs na } \\
\text { NYSE }\end{array}$} \\
\hline & Fi & $\%$ & $\mathbf{F i}$ & $\%$ \\
\hline $\begin{array}{l}\text { Total de empresas, exceto instituições financeiras, que declararam ter } \\
\text { ocorrido efeito da nova Lei no resultado }\end{array}$ & 82 & $100 \%$ & 25 & $100 \%$ \\
\hline Empresas que reapresentaram 2007 conforme as novas normas de 2008 & 34 & $41 \%$ & 17 & $68 \%$ \\
\hline $\begin{array}{l}\text { Empresas que apresentaram nas Nes a tabela de reconciliação dos efeito } \\
\text { da Lei no resultado e PL dos exercícios de } 2007 \text { e de } 2008\end{array}$ & 15 & $18 \%$ & 17 & $68 \%$ \\
\hline
\end{tabular}

\section{Impactos da Lei 11.638 nas empresas que publicaram nas NEs a Tabela de Reconciliação do}

\section{Lucro}

As tabelas 3 e 4 abordam os ICIs do Lucro Líquido $\left(\mathrm{ICI}_{\mathrm{LL}}\right)$ e do Patrimônio Líquido ( $\left(\mathrm{ICI}_{\mathrm{PL}}\right)$ apenas das empresas que publicaram nas NEs a tabela de reconciliação do efeito da nova lei para 2007 e/ou para 2008, excluindo-se as que apresentaram inconsistências. A Tabela 3, painel A, apresenta estatísticas gerais, seja da amostra completa, seja após a exclusão de três outliers, todos do LL em 2008, que representavam variações de pelo menos $800 \%$ nos resultados (ICI < -7 e ICI > 8). Após essa exclusão, o ICI $_{\text {LL }}$ médio de 2008 passa de 0,468 para 0,932 (coincidentemente, os três outliers eliminados foram números negativos: -30,9, -19,6 e -7,1). O painel C apresenta a distribuição de frequência dos ICIs da amostra completa. O painel B apresenta os resultados dos testes de média e mediana realizados.

A Tabela 3 mostra que a primeira fase de transição para o padrão internacional gerou um aumento médio da ordem de $8 \%\left(\operatorname{ICI}_{\mathrm{LL}}=1,083\right)$ no $\mathrm{LL}$, em relação à norma brasileira anterior, para as 84 empresas que o reportaram para 2007. No entanto, nota-se grande dispersão na distribuição de frequência, já que 45\% das empresas tiveram redução do LL em 2007. Por outro lado, em 2008, 2/3 das empresas tiveram redução no resultado, com efeito médio da ordem de -7\% ( $\left.\operatorname{ICI}_{\mathrm{LL}}=0,932\right)$.

O aumento do lucro médio de 2007 parece condizente com a previsão de Gray (1988), e com outros estudos citados sobre o Brasil, em relação aos US GAAP. Já a diminuição do lucro médio em 2008 parece contrariar tais predições.

Já o efeito da nova lei no PL não parece tão significativo, com queda média da ordem de 3\% nos dois exercícios, consistente com o verificado por Beckman e outros (2007) na Alemanha e Cordazzo (2008) na Itália, e noutros países, onde a harmonização tem produzido impactos menores no PL, independentemente do efeito maior ou menor verificado no lucro. 
Entretanto, na verificação da inferência para a população, o teste de médias $t$ de Student mostra não ser possível rejeitar $\mathrm{H}_{0}$ para nenhuma das mensurações; pelo contrário, esse teste mostra queda no lucro de 2008 ao nível de significância de $2 \%$.

Tabela 3 - Estatísticas para as empresas que publicaram nas NEs a reconciliação dos resultados

\begin{tabular}{|c|c|c|c|c|c|c|c|c|c|}
\hline \multirow{3}{*}{\multicolumn{2}{|c|}{ Painel A - Estatísticas Gerais }} & \multicolumn{4}{|c|}{ Exercício de 2007} & \multicolumn{4}{|c|}{ Exercício de 2008} \\
\hline & & \multirow{2}{*}{\multicolumn{2}{|c|}{$\begin{array}{c}\text { ICI }_{\text {LL }} \\
\text { Amostra } \\
\text { Completa } \\
\end{array}$}} & \multirow{2}{*}{\multicolumn{2}{|c|}{$\begin{array}{c}\text { ICI }_{\mathrm{PL}} \\
\text { Amostra } \\
\text { Completa } \\
\end{array}$}} & \multicolumn{2}{|c|}{$\mathbf{I C I}_{\mathrm{LL}}$} & \multirow{2}{*}{\multicolumn{2}{|c|}{$\begin{array}{c}\text { ICI }_{\mathrm{PL}} \\
\text { Amostra } \\
\text { Completa }\end{array}$}} \\
\hline & & & & & & $\begin{array}{c}\text { Amostra } \\
\text { Completa }\end{array}$ & $\begin{array}{c}\text { Sem } \\
\text { outliers }\end{array}$ & & \\
\hline \multicolumn{2}{|l|}{ N. de Observações } & \multicolumn{2}{|c|}{84} & \multicolumn{2}{|c|}{114} & 130 & 127 & \multicolumn{2}{|c|}{110} \\
\hline & \multicolumn{2}{|c|}{1,083} & \multicolumn{2}{|c|}{0,974} & 0,468 & 0,932 & \multicolumn{2}{|c|}{0,973} \\
\hline \multicolumn{2}{|l|}{ Mediana } & \multicolumn{2}{|c|}{1,004} & \multicolumn{2}{|c|}{0,996} & 0,979 & 0,981 & \multicolumn{2}{|c|}{0,995} \\
\hline \multicolumn{2}{|l|}{ Desvio Padrão } & \multicolumn{2}{|c|}{0,795} & \multicolumn{2}{|c|}{0,477} & 2,947 & 0,614 & \multicolumn{2}{|c|}{0,478} \\
\hline \multicolumn{2}{|l|}{ Mínimo } & \multicolumn{2}{|c|}{$-3,484$} & \multicolumn{2}{|c|}{$-0,238$} & $-30,894$ & $-3,309$ & \multicolumn{2}{|c|}{0,173} \\
\hline Máximo & & \multicolumn{2}{|c|}{4,124} & \multicolumn{2}{|c|}{1,329} & 2,675 & 2,675 & \multicolumn{2}{|c|}{1,237} \\
\hline \multicolumn{10}{|c|}{ Painel B - Testes de Média e de Mediana } \\
\hline \multirow{4}{*}{\multicolumn{2}{|c|}{$\begin{array}{l}\text { Estatística } \mathrm{t} \\
\text {-value (teste } \mathrm{t} \text { ) } \\
\text { Estatísitica } \mathrm{z} \text { (teste de Wilcoxon) } \\
\text {-value (teste de Wilcoxon) }\end{array}$}} & & & $-0,5$ & & $-2,056$ & $-1,242$ & & \\
\hline & & & & 28,3 & & $2,09 \%$ & $10,8 \%$ & & \\
\hline & & & & $-4,8$ & & $-3,379$ & $-3,149$ & & \\
\hline & & & & 0,0 & & $0,04 \%$ & $0,08 \%$ & & \\
\hline Painel C - Distribuição de Frec & quência do ICI & & & $\overline{\text { ICI }}$ & & ICl & & & \\
\hline (amostra completa) & & $\overline{F_{i}}$ & $\%$ & $\overline{F_{i}}$ & $\%$ & $\overline{F_{i}}$ & $\%$ & $\mathbf{F}_{\mathrm{i}}$ & $\%$ \\
\hline Lucro diminui $10 \%$ ou mais & $\mathrm{ICI} \leq 0,9$ & 15 & $18 \%$ & 10 & $9 \%$ & 43 & $33 \%$ & 8 & $7 \%$ \\
\hline Lucro diminui entre $5 \%$ e $10 \%$ & $0,9<$ ICI $<0,95$ & 4 & $5 \%$ & 3 & $3 \%$ & 10 & $8 \%$ & 7 & $6 \%$ \\
\hline Lucro diminui até $5 \%$ & $0,95 \leq \mathrm{ICI}<1$ & 18 & $21 \%$ & 73 & $64 \%$ & 33 & $25 \%$ & 60 & $55 \%$ \\
\hline Lucro permanece igual & $\mathrm{ICI}=1$ & - & $0 \%$ & 2 & $2 \%$ & - & $0 \%$ & 5 & $5 \%$ \\
\hline Lucro aumenta até $5 \%$ & $1<\mathrm{ICI} \leq 1,05$ & 23 & $27 \%$ & 22 & $19 \%$ & 20 & $15 \%$ & 27 & $25 \%$ \\
\hline Lucro aumenta entre $5 \%$ e $10 \%$ & $1,05<\mathrm{ICI}<1,1$ & 1 & $1 \%$ & 3 & $3 \%$ & 6 & $5 \%$ & 1 & $1 \%$ \\
\hline Lucro aumenta $10 \%$ ou mais & $\mathrm{ICI} \geq 1,1$ & 23 & $27 \%$ & 1 & $1 \%$ & 18 & $14 \%$ & 2 & $2 \%$ \\
\hline Total & & 84 & $100 \%$ & 114 & $100 \%$ & 130 & $100 \%$ & 110 & $100 \%$ \\
\hline
\end{tabular}

Por outro lado, a despeito do tamanho da amostra, ao se aplicar o teste de D'Agostino-Pearson, foi rejeitada a hipótese de normalidade da distribuição dos ICIs, prejudicando a confiabilidade do teste $t$. Assim passou-se a examinar as medianas, realizando-se o teste não paramétrico de sinais por postos de Wilcoxon, conforme painel B. Esse teste não possibilitou a rejeição de $\mathrm{H}_{0}$ para o lucro de 2007 ( $p$ value $=17 \%$ ) e indicou queda tanto no LL de 2008 como no PL dos dois períodos ao nível de significância de $1 \%$.

Assim, esses resultados parecem contrariar a previsão de Gray (1988) quanto ao conservadorismo da contabilidade brasileira tradicional, de resto confirmada nos estudos de Santos e outros (2007) e Santos e Cia (2008) sobre o Brasil em relação aos US GAAP e de outros citados estudos sobre a adoção do IFRS em países de cultura contábil eurocontinental Surge, assim, 
inevitavelmente a questão: por que tais resultados contrariariam tanto a teoria como os citados estudos sobre o Brasil e sobre países de tradição semelhante?

Buscando melhor entender as fontes dessa aparente contradição, este estudo procurou, a seguir, identificar o impacto específico de cada norma (CPC) no resultado e PL das empresas, como se evidencia na Tabela 4. A primeira coluna $\left(\mathrm{F}_{\mathrm{i}}\right)$ e segunda $(\%)$ indicam, respectivamente, o número e a frequência de empresas que registraram cada ajuste. A terceira coluna (ICP) apresenta o já mencionado Índice de Comparabilidade Parcial, que expressa o efeito de cada ajuste individual no resultado total da empresa, com base na norma anterior.

Tabela 4 - Ajustes e seus impactos nas empresas que publicaram a tabela de reconciliação do resultado

\begin{tabular}{|c|c|c|c|c|c|c|c|c|c|c|c|c|}
\hline \multirow{3}{*}{$\begin{array}{l}\text { Ajustes efetuados para adequação à } \\
\text { Lei 11.638/07 e MP 449/08 }\end{array}$} & \multicolumn{6}{|c|}{ Exercício de 2007} & \multicolumn{6}{|c|}{ Exercício de 2008} \\
\hline & \multicolumn{3}{|c|}{ Lucro Líquido } & \multicolumn{3}{|c|}{ Patrimônio Líquido } & \multicolumn{3}{|c|}{ Lucro Líquido } & \multicolumn{3}{|c|}{ Patrimônio Líquido } \\
\hline & $\overline{F_{i}}$ & $\%$ & ICP & $\overline{F_{i}}$ & $\%$ & ICP & $\mathbf{F}_{\mathrm{i}}$ & $\%$ & ICP & $\mathbf{F}_{\mathrm{i}}$ & $\%$ & ICP \\
\hline Arrendamento Mercantil Financeiro & 23 & $27 \%$ & 1,188 & 31 & $27 \%$ & 1,014 & 31 & $24 \%$ & 0,984 & 22 & $20 \%$ & 0,989 \\
\hline $\begin{array}{l}\text { Redução ao Valor Recuperável de } \\
\text { Ativos }\end{array}$ & - & $0 \%$ & & - & $0 \%$ & & 6 & $5 \%$ & 1,062 & 5 & $5 \%$ & 1,183 \\
\hline Incentivos fiscais & 10 & $12 \%$ & 1,237 & 4 & $4 \%$ & 0,994 & 23 & $18 \%$ & 1,209 & 7 & $6 \%$ & 0,979 \\
\hline $\begin{array}{l}\text { Custos de Transação e Prêmios na } \\
\text { Emissão de Títulos }\end{array}$ & 11 & $13 \%$ & 2,919 & 5 & $4 \%$ & 0,987 & 13 & $10 \%$ & 1,172 & 8 & $7 \%$ & 1,005 \\
\hline Pagamentos Baeados em Acõos & 28 & $33 \%$ & 0,955 & 10 & $9 \%$ & 0,993 & 43 & $34 \%$ & 0,925 & 17 & $16 \%$ & 0,997 \\
\hline Ajuste a Valor Presente & 27 & $32 \%$ & 0,809 & 43 & $38 \%$ & 0,986 & 66 & $52 \%$ & 0,957 & 52 & $48 \%$ & 0,994 \\
\hline $\begin{array}{l}\text { Método de Custo/Equivalência } \\
\text { Patrimonial }\end{array}$ & 8 & $10 \%$ & 0,774 & 9 & $8 \%$ & 1,001 & 11 & $9 \%$ & 0,974 & 12 & $11 \%$ & 0,982 \\
\hline Reavaliação de Ativos & 4 & $5 \%$ & 1,186 & 8 & $7 \%$ & 0,786 & 7 & $6 \%$ & 1,083 & 6 & $6 \%$ & 0,960 \\
\hline Capitalização de Despesas (Diferido) & 35 & $42 \%$ & 0,629 & -42 & $37 \%$ & 1,004 & 36 & $28 \%$ & 0,927 & 29 & $27 \%$ & 0,990 \\
\hline Valor Justo de Instrumentos Financeiros & 33 & $39 \%$ & 1,029 & 45 & $39 \%$ & 1,003 & 58 & $46 \%$ & 0,984 & 47 & $44 \%$ & 0,967 \\
\hline $\begin{array}{l}\text { Efeitos de mudanças nas taxas de } \\
\text { câmbio e conversão de Demonstrações } \\
\text { contábeis }\end{array}$ & 19 & $23 \%$ & 1,097 & 2 & $2 \%$ & 0,857 & 28 & $22 \%$ & 0,945 & 15 & $14 \%$ & 1,010 \\
\hline Efeitos tributários sobre os Ajustes & 43 & $51 \%$ & 0,927 & 52 & $46 \%$ & 1,000 & 61 & $48 \%$ & 0,966 & 46 & $43 \%$ & 1,000 \\
\hline Outros efeitos & 25 & $30 \%$ & 1,039 & 34 & $30 \%$ & 1,002 & 29 & $23 \%$ & 1,015 & 37 & $34 \%$ & 1,003 \\
\hline Total & 84 & & 1,083 & 114 & & 0,974 & 127 & & $\mathbf{0 , 9 3 2}$ & 108 & & 0,974 \\
\hline
\end{tabular}

Pela análise da Tabela 4, pode-se verificar que no exercício de 2007, embora o aumento médio no resultado tenha sido, como mencionado, de apenas $8,1 \%$, vários ajustes individuais geraram efeitos bem mais expressivos. Assim, ao serem excluídos do resultado os custos de transação na emissão de títulos, como previsto na nova norma, tal gerou uma elevação em média de três vezes $(\mathrm{ICP}=2,919)$ no resultado das 11 empresas que registraram este que foi o maior ajuste identificado em 2007. O segundo ajuste em magnitude, com um efeito médio de $-39 \%$ no resultado $(\mathrm{ICP}=0,612)$, decorreu da proibição 
de capitalização de despesas com pesquisa, gastos pré-operacionais e assemelhados, antes largamente praticada, como mostra sua ocorrência em 36 empresas (43\%).

Outro ajuste que também aumentou significativamente o Lucro de 2007 foi o lançamento dos incentivos fiscais no resultado em vez de nas Reservas de Capital (ICP = 1,237). Em seguida, elevando o Lucro em 19\% (ICP = 1,188) em média, figura o ajuste decorrente do reconhecimento do leasing financeiro (arrendamento mercantil) como compra financiada. Tal confirma a expectativa de que muitas empresas, ao praticarem o leasing financeiro, usufruíam de benefícios fiscais no imposto de renda, dado que o valor da prestação do arrendamento era maior do que o valor da depreciação do ativo, mais juros.

O ajuste decorrente da proibição da reavaliação de ativos teve impacto de magnitude semelhante: o estorno da depreciação a maior decorrente da reavaliação gerou um aumento da ordem de $19 \%$ no resultado e uma redução média de $-22 \%$ no PL das empresas que baixaram reavaliações efetuadas anteriormente (este é, destacadamente, o ajuste que mais impactou o PL das empresas). É de se notar que nem todas as empresas efetuaram essa baixa da reavaliação, conforme facultado pelo CPC 13. De fato, a partir da base de dados Economática, verifica-se que $64 \%$ das empresas que apresentavam saldo na conta Reserva de Reavaliação no exercício de 2006 ainda o mantinham em 2008. Surpreendentemente, em 2007, oito empresas excluíram a Reserva de Reavaliação do PL, mas apenas quatro eliminaram do resultado o efeito da reavaliação na depreciação, o que indicaria uma inconsistência no lançamento desse ajuste.

Note-se que, neste ponto, a Lei 11.638/07 contradiz sua própria determinação de harmonização com o padrão IFRS, já que proíbe a reavaliação de ativos quando esta é permitida pelo padrão internacional, o que faz surgir necessariamente a questão: seria viável a harmonização contábil internacional se cada país aplicasse apenas o subconjunto de IFRSs que melhor lhe conviesse? A harmonização sobreviveria a "vários IFRSs de cada país"?

Quanto aos ajustes que reduziram o LL de 2007, destacam-se, além da já mencionada extinção do ativo diferido, diferenças na aplicação do método de equivalência patrimonial $($ ICP $=0,774)$ e o ajuste a valor presente $(\mathrm{ICP}=0,809)$ de recebíveis e exigíveis de longo prazo (e de curto prazo, quando relevante).

Comparando-se os resultados do exercício de 2007 com os de 2008, nota-se que o ajuste de “custos de transação na emissão de títulos" parece ter sido o principal fator que provocou a mencionada inversão de sinal do resultado (de um aumento de 8\% em 2007 para uma redução de -7\% em 2008). 
Com efeito, o impacto deste ajuste triplicaria o LL de 2007, mas aumentaria em apenas 9\% o LL de 2008.

A oscilação no comportamento deste e de outros ajustes levanta outra questão: até que ponto teriam sido os efeitos contábeis da primeira fase da migração para o padrão IFRS contaminados por fatores econômicos exógenos, como a crise financeira global de 2008 ?

A esse respeito, os resultados constantes da Tabela 4, embora relevantes para a análise censitária, apresentam uma limitação: a maior parte das empresas que publicaram a tabela de reconciliação do lucro e PL do exercício de 2007 não o fez em 2008, e a grande maioria das empresas, aproveitando a faculdade dada pelo CPC 13 de efetuar a transição para as novas regras apenas em 01/01/2008, não publicou o efeito da nova lei no resultado de 2007. Ou seja, a discrepância nos resultados entre 2007 e 2008 pode ter sido gerada não pela ocorrência de uma variável exógena, como a crise financeira mundial, mas porque os resultados de 2007 e os de 2008 seriam de empresas diferentes, prejudicando a comparação.

Objetivando superar essa limitação, a análise das tabelas de reconciliação do resultado foi refinada para incluir apenas as empresas que publicaram em tal tabela os efeitos sobre os exercícios tanto de 2007 como de 2008. Essa análise está apresentada a seguir.

\section{Efeitos da Lei 11.638 nas empresas que publicaram a Tabela de Reconciliação do Resultado em ambos os exercícios, 2007 e 2008, e impactos da Crise Financeira de 2008}

Conforme indicado na Tabela 1, apresentada anteriormente, dentre as 232 empresas que, de formas diversas, divulgaram os efeitos da adoção inicial da nova lei, destaca-se a subpopulação de 34 empresas que, além de terem reapresentado as demonstrações de 2007 conforme as novas normas, publicaram em NE a tabela de reconciliação dos efeitos da nova lei nos dois exercícios (2007 e 2008). Essas 34 empresas mostram ter conseguido, mesmo em meio à sucessão conturbada de normas da adoção inicial da nova lei, elaborar demonstrações que alcançaram tanto um alto grau de confiabilidade como o full disclosure das informações.

Como mostra uma primeira análise descritiva da Tabela 5, a nova norma trouxe um aumento de 25,8\% no LL reportado em 2007, mas em 2008 levou a uma queda de -15,6\%.

Quanto ao lucro de 2007, tanto o teste de média ( $t$ de Student) como o de mediana (Wilcoxon) rejeitam $\mathrm{H}_{0}$, corroborando a hipótese de conservadorismo da contabilidade brasileira, com a tendência a aumento de lucros a partir da migração do IFRS extensível à população das empresas abertas. 
Tabela 5 - Estatísticas das 34 empresas que publicaram nas NEs a reconciliação dos resultados de 2007 e 2008

\begin{tabular}{|c|c|c|c|c|c|}
\hline \multirow{2}{*}{\multicolumn{2}{|c|}{ Painel A - Estatísticas Gerais }} & \multicolumn{2}{|c|}{ Exercício de 2007} & \multicolumn{2}{|c|}{ Exercício de 2008} \\
\hline & & $\mathbf{I C I}_{\mathbf{L L}}$ & $\mathbf{I C I}_{\mathbf{P L}}$ & $\mathbf{I C I}_{\mathbf{L L}}$ & $\mathbf{I C I}_{\mathbf{P L}}$ \\
\hline Média & & 1,258 & 0,992 & 0,844 & 0,967 \\
\hline Mediana & & 1,005 & 0,996 & 0,987 & 0,996 \\
\hline Desvio Padrão & & 0,848 & 0,038 & 0,791 & 0,152 \\
\hline Mínimo & & 0,087 & 0,881 & $-3,309$ & 0,173 \\
\hline Máximo & & 4,124 & 1,094 & 1,943 & 1,237 \\
\hline \multicolumn{6}{|c|}{ Painel B - Testes de Média e de Mediana } \\
\hline \multirow{4}{*}{\multicolumn{2}{|c|}{$\begin{array}{l}\text { Estatística } \mathrm{t} \\
p \text {-value (teste } \mathrm{t} \text { ) } \\
\text { Estatísitica } \mathrm{z} \text { (teste de Wilcoxon) } \\
\text { p-value (teste de Wilcoxon) }\end{array}$}} & 1,775 & $-1,254$ & $-1,149$ & $-1,267$ \\
\hline & & $4,3 \%$ & $10,9 \%$ & $12,9 \%$ & $10,7 \%$ \\
\hline & & 1,510 & $-2,087$ & $-1,624$ & $-2,714$ \\
\hline & & $6,6 \%$ & $1,8 \%$ & $5,2 \%$ & $0,3 \%$ \\
\hline \multirow{2}{*}{\multicolumn{2}{|c|}{ Painel C - Distribuição de Frequência do ICI $_{L L}$}} & \multicolumn{2}{|c|}{ ICI $_{L L}$ de 2007} & \multicolumn{2}{|c|}{ ICI $_{L L}$ de 2008} \\
\hline & & $\mathbf{F}_{\mathrm{i}}$ & $\%$ & $\mathbf{F}_{\mathrm{i}}$ & $\%$ \\
\hline Lucro diminui $10 \%$ ou mais & $\mathrm{ICI} \leq 0,9$ & 6 & $18 \%$ & 11 & $32 \%$ \\
\hline Lucro diminui entre $5 \%$ e $10 \%$ & $0,9<\mathrm{ICI}<0,95$ & 1 & $3 \%$ & 1 & $3 \%$ \\
\hline Lucro diminui até $5 \%$ & $0,95 \leq \mathrm{ICI}<1$ & 5 & $15 \%$ & 11 & $32 \%$ \\
\hline Lucro permanece igual & $\mathrm{ICI}=1$ & - & $0 \%$ & - & $0 \%$ \\
\hline Lucro aumenta até $5 \%$ & $1<\mathrm{ICI} \leq 1,05$ & 12 & $35 \%$ & 7 & $21 \%$ \\
\hline Lucro aumenta entre $5 \%$ e $10 \%$ & $1,05<\mathrm{ICI}<1,1$ & - & $0 \%$ & - & $0 \%$ \\
\hline Lucro aumenta $10 \%$ ou mais & $\mathrm{ICI} \geq 1,1$ & 10 & $29 \%$ & 4 & $12 \%$ \\
\hline Total & & 34 & $100 \%$ & 34 & $100 \%$ \\
\hline
\end{tabular}

Quanto aos demais números, tal não ocorre: o teste $t$ de Student não rejeita $\mathrm{H}_{0}$ para nenhuma dessas mensurações, enquanto o teste de Wilcoxon indica o contrário da hipótese, ao mostrar, ao nível de significância de 5\%, uma queda tanto no LL de 2008 quanto no PL dos dois anos.

Verifica-se, assim, uma contradição entre a corroboração do aumento do LL de 2007 e a indicação contrária da redução do LL de 2008.

Tal contradição leva a investigação a examinar eventuais fatores externos que possam ter influenciado em sentido contrário os resultados desses dois anos.

Ora, os resultados da Tabela 6 parecem denotar que o efeito da adoção inicial da nova lei terá sofrido impactos da crise financeira internacional em 2008. De fato, observa-se uma mudança de tendência justamente nos ajustes que mais teriam sofrido o efeito da crise (assinalados em cinza na tabela).

Assim, a crise financeira teria influenciado no ajuste "custos de transação na emissão de títulos". Como mencionado, ao contrário da regra anterior no Brasil, a nova norma internacional determina excluir do resultado os "custos de transação na emissão de títulos" e seu tratamento como 
redução do valor captado. Observa-se que o impacto desse ajuste em 2007 quadruplicaria o resultado das empresas (ICP = 4,110). Já em 2008 esse ajuste provocaria um aumento de apenas 24\% (ICP = 1,241). Dados da Bovespa indicam razões desse impacto, como o número de emissões de ações caindo 84\% (de 76 em 2007 para 12 em 2008) e o volume captado caindo 51\% (de R 70 bilhões em 2007 para $\mathrm{R} \$ 34$ bilhões em 2008).

Tabela 6 - Índices de Comparabilidade Parcial (ICPs) das 34 empresas que publicaram a tabela de reconciliação do resultado e efeitos da crise financeira mundial de 2008

\begin{tabular}{|c|c|c|c|c|}
\hline & \multicolumn{2}{|c|}{ Exercício de 2007} & \multicolumn{2}{|c|}{ Exercício de 2008} \\
\hline & $\mathrm{IC}_{\mathrm{LL}}$ & $\mathrm{IC}_{\mathrm{PL}}$ & $\mathrm{IC}_{\mathrm{LL}}$ & $\mathrm{IC}_{\mathrm{PL}}$ \\
\hline Valor conforme Lei 6.404/76 (regras até 2007) & 1 & 1 & 1 & . \\
\hline Arrendamento Mercantil Financeiro & 0,963 & 0,994 & 0,969 & 0,992 \\
\hline Redução ao Valor Recuperável de Ativos & & & 0,988 & 0,992 \\
\hline Incentivos fiscais & 1,226 & 0,911 & 1,222 & 0,931 \\
\hline $\begin{array}{l}\text { Custos de Transação e Prêmios na Emissão de } \\
\text { Títulos }\end{array}$ & 4,110 & 1,000 & 1,241 & 1,004 \\
\hline Pagamentos Baseados em Ações & 0,914 & 0,992 & 0,960 & 0,996 \\
\hline Ajuste a Valor Presente & 0,848 & 0,995 & 0,969 & 0,994 \\
\hline Método de Custo/Equivalência Patrimonial & 0,712 & 1,002 & 0,878 & 0,975 \\
\hline Reavaliação de Ativos & 1,001 & 0,999 & 1,097 & 1,023 \\
\hline Capitalização de Despesas (Diferido) & 0,614 & 0,990 & 0,923 & 0,990 \\
\hline Valor Justo de Instrumentos Financeiros & 1,008 & 1,008 & 0,826 & 0,953 \\
\hline $\begin{array}{l}\text { Efeitos de mudanças nas taxas de câmbio e } \\
\text { conversão de Demonstrações contábeis }\end{array}$ & 1,014 & 0,857 & 1,162 & 1,033 \\
\hline Efeitos tributários sobre os Ajustes & 0,939 & 1,003 & 0,955 & 1,003 \\
\hline Outros efeitos & 1,065 & 1,017 & 0,928 & 1,029 \\
\hline $\begin{array}{l}\text { Valor conforme Lei 11.638/07 e MP 449/08 } \\
\text { (regras de 2008) }\end{array}$ & 1,258 & 0,992 & $\mathbf{0 , 8 4 4}$ & 0,967 \\
\hline
\end{tabular}

Outra indicação do impacto da crise financeira aparece no ajuste do "valor justo (marcação a mercado) de instrumentos financeiros", antes mantidos ao preço de custo. Tal ajuste teve efeito praticamente nulo (ICP $=1,008$ ) em 2007 e um decréscimo de $18 \%$ (ICP $=0,826)$ no resultado de 2008, o que denota um reflexo da desvalorização geral desses instrumentos (o Ibovespa fechou $41 \%$ menor em 2008 em relação a 2007).

Talvez uma simulação, na forma de um Gedankenexperiment, ou experimento meramente mental, possa ilustrar o impacto da crise de 2008 nesses dois ajustes. Se as sete empresas que reportaram o ajuste "custos de emissão de títulos" em 2007 o tivessem feito também em 2008 aos mesmos valores absolutos, o ICP seria de 2,554 (em vez de 1,241). Já no ajuste "marcação a mercado", a repetição dos valores absolutos de 2007 em 2008 levaria a um ICP de 1,059 (em vez de 0,826). Com 
esses novos valores dos dois ajustes, o ICI de 2008 passaria a 1,067 (em vez de 0,844), superando a referida contradição entre os efeitos da lei em 2007 e 2008, e confirmando nos dois anos, dentro das restrições dessa simulação, o conservadorismo da contabilidade brasileira.

Já em sentido contrário aos dois ajustes anteriores, o efeito do ajuste "mudanças na taxa de câmbio e conversão das demonstrações contábeis" passa de inexpressivo em 2007 (ICP = 1,014) para um aumento de $16 \%$ em 2008 (ICP = 1,162), refletindo a desvalorização de $32 \%$ do real (taxas de 1,77 em 2007 versus 2,33 no final de 2008).

\section{CONCLUSÃO}

Este estudo pretende ter contribuído para a análise do efeito da Lei 11.638/07 e da MP 449/08 no resultado das empresas brasileiras abertas, na primeira fase, ora em curso, do processo de harmonização da contabilidade brasileira com o padrão internacional.

Foi observado um baixo grau de compliance das empresas com as normas de adoção inicial da nova lei e uma grande diversidade na forma de aplicação das novas normas entre as empresas. Em detrimento da transparência, das 318 empresas analisadas, apenas $28 \%$ reapresentaram as demonstrações de 2007 conforme as regras de 2008 para fins de comparação, e somente 11\% apresentaram em NE a reconciliação do efeito da nova lei no resultado e PL dos dois anos. A transparência também não foi privilegiada entre as empresas mais voltadas à excelência nesse quesito, como as do novo mercado da Bovespa: das que declararam haver efeito da nova lei, apenas $41 \%$ reapresentaram os balanços de 2007 e somente $18 \%$ publicaram a tabela de reconciliação dos dois anos. Já dentre as emissoras de ADRs na NYSE, apenas 68\% seguiram essas duas políticas de maior disclosure.

Essa deficiência no grau de compliance com as novas normas, somada à grande diversidade na aplicação da norma entre as empresas resultante do exercício das várias opções de cumprimento deixadas às empresas, e ao baixo grau de transparência na informação sobre os efeitos das novas normas nos números das empresas, certamente dificultaram o trabalho dos analistas, o que teria justificado a constatação da imprensa especializada de certa "confusão contábil”" (NIERO e outros, 2009) que teria prejudicado a análise dos balanços de 2008.

Foi verificada, ainda, uma inconsistência no efeito da nova lei sobre os resultados reportados pelas empresas nos exercícios de 2007 e de 2008: dentre as 175 empresas que publicaram a tabela de 
reconciliação do resultado de 2007 e/ou 2088 em NE, apurou-se um aumento médio de 8,1\% no resultado de 2007 e uma diminuição média de -7\% em 2008. No entanto, a despeito do razoável tamanho da amostra, o teste de média $t$ de Student não confirmou a possibilidade de generalização desses resultados ao nível de significância de $10 \%$.

Ao se reduzir a amostra às 34 empresas que apresentaram a tabela de reconciliação do resultado nos dois anos, permitindo comparação mais precisa e consistente, foi possível perceber que algumas inconsistências entre os efeitos em 2007 e 2008 estariam correlacionadas a impactos da crise financeira global, expressos em dois ajustes principais ao resultado: “custos de transação na emissão de títulos" e “marcação a mercado de instrumentos financeiros". Ao efetuar-se uma simulação mental, mantendo-se em 2008 os valores de 2007 desses dois ajustes para eliminar efeitos da crise, obter-se-ia um ICI positivo também para 2008. Isso reforçou, embora com as restrições da simulação, a associação da queda nos resultados de 2008 ao efeito exógeno da crise financeira global, na linha da previsão de Gray (1988) de conservadorismo da contabilidade tradicional brasileira, de resto confirmada também em outros estudos.

Assim, dentro das limitações da amostragem das empresas que reportaram 2007 e 2008, talvez se possa preconizar que a adoção do "full IFRS” em 2010, ou sua antecipação pelas empresas, tenderá a demonstrar mais claramente resultados superiores em relação à contabilidade tradicional brasileira, inclusive diante dos reportados neste início de transição.

Além da restrição de amostras não aleatórias, algumas dificuldades prejudicaram a análise mais precisa do impacto da migração para o padrão internacional no resultado das empresas: o processo conturbado de regulação, que teria deixado pouco tempo para a maioria das empresas se adaptarem à nova contabilidade; a estratégia adotada pelos órgãos reguladores, de dividir a implantação do padrão internacional em duas fases, diluindo o impacto das novas normas no resultado das empresas e dificultando a comparação com pesquisas realizadas sobre a migração em outros países; a faculdade dada às empresas de escolherem entre duas datas de transição para as novas normas, impossibilitando o cálculo do efeito da migração em todas as empresas em um mesmo exercício; e, finalmente, a coincidência do primeiro momento de transição com uma das mais graves crises financeiras mundiais desde 1929.

Seria de recomendar às empresas e reguladores investir mais na transparência e comparabilidade durante este período de transição até o full IFRS em 2010, pelo menos publicando em Nota Explicativa a tabela de reconciliação do resultado informações suficientes para permitir mais clara confrontação entre os três conjuntos normativos: o padrão tradicional brasileiro anteriormente vigente, 
as normas da atual primeira fase de transição e o full IFRS. Essa evidenciação - até que tenha sido assimilado plenamente o padrão internacional nos próximos anos - contribuiria para um melhor ajuste de expectativas, diminuição da assimetria da informação e aumento da eficiência do mercado.

\section{NOTA DE AGRADECIMENTO}

O presente artigo baseia-se em pesquisa financiada pela Escola de Administração de Empresas de São Paulo, da Fundação Getulio Vargas. Colaboraram a assistente de pesquisa Laura Calixto, no levantamento bibliográfico, e o monitor de pesquisa Aleksander Ridel Juzwiak, na coleta de dados.

\section{REFERÊNCIAS}

ADAMS, C. A, WEETMAN, P; GRAY, S. J. Reconciling national to International Accounting Standards: Lessons from a study of finnish corporate reports. The European Accounting Review, v. 2, n. 3, p. 471-494, 1993.

BRASIL, Lei nº 11.638 de 28/12/2007. Disponível em: http://www.cvm.gov.br. Acesso em 10.01.2008.

BRASIL, Lei $n^{\circ} 11.941$ de 27/05/2009. Conversão da Medida Provisória no 449 de 03/12/2008 (MP 449/08) em Lei. Disponível em: http://www.cvm.gov.br/. Acesso em 30.05.2009.

BECKMAN, J; BRANDES, C; EIERLE, B. German reporting practices: an analysis of reconciliation from German commercial code to IFRS or US GAAP. Advances in International Accounting, v. 20, p. 253-294, 2007.

BIANCONI, C. Empresas "perdem” R\$ 10 bi com novas regras contábeis. Jornal O Estado de S. Paulo, São Paulo, 25.03.2009.

COOKE, T. E. The impact of accounting principles on profits: the US versus Japan. Accounting and Business Research, v. 23, n. 92, p. 460-476, 1993.

CORDAZZO, M. The impact of IAS/IFRS on accounting practices: evidence from Italian listed companies. In Séminaire DEMA/ERM, 2008. Disponível em: 
http://www.hec.unil.ch/irm/Research/Seminaire. Acesso em 14.05.2009.

CVM - Comissão de Valores Mobiliários. Instruções e Deliberações. Disponível em: www.cvm.gov.br. Acesso em 15.08.2009.

CPC - Comitê de Pronunciamentos Contábeis. Pronunciamentos Técnicos. Disponível em: www.cpc.com.br. Acesso em 15.08.2009.

DING Y; JEANJEAN, T; SOTOLOWY, H. Why do national GAAP differ from IAS? The role of culture. The International Journal of Accounting, v. 40, n. 4, p. 325-350, 2005.

DOUPNIK, T. S; RICCIO, E. L. The influence of conservatism and secrecy on the interpretation of verbal probability expressions in the Anglo and Latin culture areas. The International Journal of Accounting, v. 41, n. 3, p. 237-261, 2006.

GRAY, S. J. The impact of international accounting differences from a security analysis perspective: some European evidence. Journal of Accounting Research, v. 18, n.1, p. 64-76, 1980.

GRAY, S. J. Towards a theory of cultural influence on the development of accounting systems internationally. Abacus, v. 24, n. 1, p. 1-15, 1988.

HELLMAN, N. A comparative analysis of the impact of accounting differences on profits and return on equity: Differences between Swedish practice and US GAAP. The European Accounting Review, v. 2, n. 3, p. 495-530, 1993.

IASC Foundation. A Guide through IFRS. London: 2009.

LEMES, S; CARVALHO, L. N. G; OLIVEIRA-LOPES, L. C. Comparabilidade entre os BR GAAP e os US GAAP: algumas evidências das companhias brasileiras listadas na NYSE. In: ENCONTRO NACIONAL DA ASSOCIAÇÃO NACIONAL DOS PROGRAMAS DE PÓS-GRADUAÇÃO EM ADMINISTRAÇÃO, 31, Anais. Rio de Janeiro, ANPAD, 2007. 
ARTIGO - IMPACTOS DO INÍCIO DA HARMONIZAÇÃO CONTÁBIL INTERNACIONAL (LEI 11.638/07) NOS RESULTADOS DAS EMPRESAS ABERTAS

Edilene Santana Santos e Laura Calixto

NIERO, N. Novas regras prometem emoções fortes. Valor Econômico, São Paulo, 13.06.2008.

NIERO N; VALENTI, G; D’AMBROSIO, D. Confusão contábil prejudica análise de balanços de 2008. Valor Econômico, São Paulo, 09.03.2009.

NIYAMA, J. K. Contabilidade Internacional. São Paulo: Atlas, 2005.

NOBES, C; PARKER, R. Comparative International accounting. Harlow: Pearson, 2006.

NORTON, J. The impact of financial accounting practices on the measurement of profit and equity: Australia versus United States. Abacus, v. 31, n. 2, p. 178-200, 1995.

O'CONNELL, V; SULLIVAN, K. The impact of mandatory conversion to IFRS on the net income of FTSEurofirst 80 firms. Journal of Applied Research in Accounting and Finance, v. 3, n. 2, p. 17-26, 2008.

RADEBAUGH, L. H; GRAY, S. J; BLACK, E. L. International accounting and multinational enteprises. Hoboken, NJ: Wiley, 2006.

SANTOS, E. S; CIA, J. N. S; CIA, J. C. US GAAP x normas brasileiras: há diferenças significativas no valor do lucro reportado pelas empresas brasileiras com ADRs na NYSE? In: ENCONTRO NACIONAL DA ASSOCIAÇÃO NACIONAL DOS PROGRAMAS DE PÓS-GRADUAÇÃO EM ADMINISTRAÇÃO, 31, 2007, Anais. Rio de Janeiro: ANPAD, 2007.

SANTOS, E. S; CIA, J. N. S; CIA, J. C. US GAAP x contabilidade em países da América Latina: mensuração do impacto das diferenças de normas no lucro reportado pelas empresas com ADRs na NYSE. In: CONGRESSO UNIVERISDADE DE SÃO PAULO DE CONTROLADORIA E CONTABILIDADE, 8, 2008, Anais. São Paulo: FEA-USP, 2008.

SANTOS, E. S; CIA, J. N. S. Expected impacts of the international accounting harmonization on the profit of Brazilian companies based on differences between BR GAAP / US GAAP reported by issuers 
of ADRs in the NYSE. In: ASIAN PACIFIC CONFERENCE ON INTERNATIONAL ACCOUNTING ISSUES, 20, 2008, Anais. Paris, 2008.

SAUDAGARAN, S. M. International Accounting: a user perspective. Mason, OH: Thomson, 2001.

SCHROEDER, R. G; CLARK, M. W; CATHEY, J. M. Financial accounting: theory and analysis. 7. Ed. New York: Wiley, 2001.

VALENTI, G; FREGONI, S. Lei contábil gera ajustes milionários. Valor Econômico. São Paulo, 02.06.2008.

WEETMAN, P. E; GRAY, S. J. International analysis and comparative corporate performance: the impact of UK versus US accounting principles on earnings. Journal of International Financial Management and Accounting, v. 2, n. 2-3, p. 112-130, 1990.

WEETMAN, P. E; GRAY, S. J. A comparative international analysis of the impact of accounting principals on profits: the USA versus the UK, Sweden and the Netherlands. Accounting and Business Research, v. 21, n. 83, p. 363-379, 1991.

WEETMAN, P. E. e outros. Profit measurement and UK accounting standards: a case of increasing disharmony in relation to US GAAP and IASs. Accounting and Business Research, v. 28, n. 3, p.189208, 1998. 